\title{
Simple Remarks of The True Story of Ah $Q$ and Chi Pheo
}

\author{
Van-Dau Quach (Wendou Guo) \\ School of Chinese Language and Literature, Hunan University, Hunan, China
}

\begin{abstract}
Ah Q and Chi Pheo are two typical figures created by two writers, Lu Xun of China and Nam Cao of Vietnam. Authors use the typical method to create the artistic image which has the distinct individuality and can reflect certain social essence. "Ah Q" and "Chi Pheo" though in different nationalities and different age (Ah Q in the modern history stage 1911, Chi Pheo in the modern history of stage 1941), but both are in the historical stage of the Eastern feudal society. Therefore, it can be considered that Lu Xun and Nam Cao are contemporaries. Besides, these two writers are deeply interested in the subject matter of the underclass farmers, so there are differences between the two typical characters. It is not surprising that the characters of "Ah Q" and "Chi Pheo" walk from the novel to the screen, from the big screen to every corner of the lives of the people of the two countries, let the past. Present and future people can not forget them. Through the method of portraying characters, readers can further understand Lu Xun and Nam Cao's creative art thoughts. The social environment and historical background behind the fate of the characters. This paper attempts to find out the similarities and differences of the writers in portraying the art of the characters. Creative resonance and display of literary exchanges between the two countries.
\end{abstract}

Keywords: Ah Q, Chi Pheo, Nam Cao, Lu Xun, contrast characters

\section{The Content of “Chi Pheo" and “Ah Q”}

In Vietnam, Chinese literature courses have been taught since high school, which focuses on the content of Chinese modern and contemporary literature. Lu Xun is known as one of the most influential foreign writers in the literary world of Vietnam. Reading Lu Xun's works, Vietnamese readers seem to have seen the back of Vietnamese realistic writer Nam Cao. Two great writers, one in China and one in Vietnam, are in a different historical, cultural, and linguistic background, but they have struck a chord in their creation. They have a similar perspective on the social background of their country and the tragedy of the peasants' fate. In Nam Cao's "Chi Pheo ", the "Ah Q" in Lu Xun's "Ah Q" is the most typical representative of the peasant image.

In Vietnam and also in the semi-feudal and semi-colonial China under the background of the "chi gone with the wind" and "The True Story of Ah Q" will also speak out against the feudal land owners to farmers at the sin, shaped the $\mathrm{Q}$ and chi float so oppressed by the old heavy and spirit have been distorted images:

Van-Dau Quach (Wendou Guo), Doctor, School of Chinese Language and Literature, Hunan University, Hunan, China; Military Academy of Sciences, Hanoi, Vietnam. 
Table 1

The Main Character in the Work

\begin{tabular}{|l|l|l|}
\hline & 《The true story of Ah Q》 & 《Chi Pheo \\
\hline The landlord & Grandpa Zhao, Grandpa Qian & Ba Kien \\
\hline Farmer & Ah Q, little D, Wang Hu & Soldier, Chi Pheo, Nam Tho \\
\hline
\end{tabular}

In Nam Cao and Lu Xun's works, the landlord power demonstration scene was pulled down. The maoists that they used to use as oppressors were debunked. What remains is the fate of the poorest working people under society.

"The True Story of $A h Q$ " criticizes the failed asset revolution. The revolution did not have the revolutionary meaning of the revolution, the revolution often makes people more frightened, more hurried, only Ah $Q$ one person felt elated. Ah Q believes that the revolution is stealing rich people's money as their own, is to do "thief". Because of the misunderstanding of the word "revolution", Ah Q has reached the end of the road and suffered a tragic fate. It was the shadow of the 1911 revolution, a revolution that was not in place. The revolution of 1911 overthrew the feudal monarchy for more than two thousand years and made the concept of democratic republic deeply popular, but it did not complete the great task of anti-imperialist and anti-feudal democratic revolution. The bourgeoisie rejected the peasants who had a strong revolutionary demand. Therefore, after the revolution, the peasants were still under the cruel exploitation and oppression of imperialism and feudalism, and suffered from political oppression, economic exploitation and spiritual enslavement. While criticizing the revolution, Lu Xun also began to sprout the idea of a new democratic revolution. He wanted to arouse the peasants' awareness of the real revolution.

Chi Pheo is created after 20 years when The True Story of $A h Q$ was written, but there are not enough to show people's revolutionary struggle on the high, maybe meteorological 'morality is a patriotic intellectuals, has yet to sprout new democratic revolutionary ideas. Therefore, there are similarities and differences between Ah Q and Chi Pheo

\section{“Chi Pheo" and "The True Story of Ah Q" Prosecute the Feudal Forces and Show Mercy to the Poor Working People}

Both books accuse the feudal landlords of the evil of exploitation by the peasants, revealing the true face of the rich people. They represent the feudal rulers in order to maintain their own rule, the adoption of violent repression and spiritual slavery policy, the use of feudal ethics, feudal superstition and ignorance policy. The Nam Cao and Lu Xun face such realistic society to express hate, to at that time the poor working people all expressed deep understanding and sympathy. Soldiers, Chi Pheo, Nam Tho, Ah Q, little D, Wang and other people's fate will sooner or later in the society at the bottom of the tragedy, which makes Nam Cao and Lu Xun moment of compassion. Why, then do the two great writers resonate with the same creation? It can be understood that, out of the social and historical background of the two countries (Semi-feudal and semi-colonial) the feudal forces desperately oppression, exploitation of the working people led to farmers lost land, most do farm, Ober Wutsenwa, the afternoon. More importantly, the two writers devote themselves to the practice of social life to understand the plight of the working people, to grasp their character and fate, and to have a common voice in humanitarianism, so that "Chi Pheo" and "Ah Q" came together, there are many similarities on the content. 


\section{“The True Story of $A h Q$ “Criticizes the Asset Revolution.}

The "revolution" mentioned in Lu Xun's novels came out of the blue, so that the people in the Wei Village always felt suddenly. No one knew the outbreak of the revolution, so no one knew the nature of the revolution. After the revolution, all the people in the Wei Village were in a state of panic and fear. Only Ah Q, who was not afraid, greeted the "revolution" with joy and was willing to participate in the revolution. He thought that the "revolution" was "to be a thief", which meant to rob the rich people's money for themselves. The failed asset revolution and the peasants lack of knowledge of the revolution were met with disastrous results.

At the same time, it directly affected Vietnam, which was struggling with semi-feudal and semi-colonial power. But there is also no specific content in the work "Chi Pheo" written by Nam Cao, because of the subjective factors of the writer himself. In the 1920s, although Lu Xun was not a man of the revolutionary road, he had the idea of a new democratic revolution. He had the courage to fight and criticize the incomplete Revolution of 1911, which showed that Mr. Lu Xun had a thorough revolutionary idea. He debunked the Ah Q's naive knowledge of the revolution and satirized the Ah Q's crude opinions of the revolution, which proved that Lu Xun always hoped that the peasants must have revolutionary ideas. On the contrary, Nam Cao is a purely patriotic literary intellectual man, completely devoid of revolutionary ideas. This point is related to the fact that although the asset revolution didn't happen in Vietnam, after the Ambai Uprising it continued to erupt in the following insurrection, such as yijing Soviet, beishan, duliang, and southern period. In the 20 years after the "The True Story of Ah Q", but Nam Cao in the book of "Chi Pheo" sustains a strong sense of the people's revolutionary struggle.

\section{The Typical Characters of "Chi Pheo" and "Ah Q".}

\section{The Aspiration and the $Q$ both Lead a Poor Life, and Have a Contradictory and Deformed Character Poor life.}

Ah $\mathrm{Q}$ is also a victim of suffering. The two of them have endured hardships and sufferings in spirit and substance. Chi Pheo was abandoned in the absurd pit, lonely existence, finding nothing, wandering the streets. Ah Q has no history, no identity, no family. In order to maintain their lives, they only work on farm labourers, suffering and suffering. Although they both want to work for a safe life, they cannot as quiet as they think. His life has almost turned into a more tragic and desperate page since he met his wife, who had not thought of him for thousands of years. Ah Q also hopes that the revolution can change thats life, but the reality is counter productive.

\section{Personality conflict and disintegration.}

The life of Chi Pheo and Ah Q is often in the passive state controll by the environment. Therefore, they have to becoming unnormal people for a long time, with contradictions and degenerate characters. I have always been kind to people, suddenly became a sly and malicious "evil spirit"; From a very well known gift to a man of character, he became a man who has no consciousness of his actions; From a complacent person, before the old fox bully meeting, but timid. Ah Q is also the same, when the character is cold and hot, when good and bad, sometimes the bully, sometimes the timid, or Sometimes arrogant, sometimes self-abased, Sometimes the feudal thought, but sometimes the instinct of consciousness. Its indeed that nangao and Lu Xun have struck a chord in shaping the image of peasants. 


\section{The General Meaning of "Spiritual Victory Law” Ah Q Typical Character.}

Despite living a life of poverty and suffering, Ah Q always had the illusion of victory, and in any case, Ah Q was the winner. He always believed that he was better than anyone else, and that he had more authority than others, more children than others, and more knowledge than others. In fact, his life is very bad, relying only on the “spiritual victory law" can exist. Lu Xun's criticism of Ah Q's "spiritual victory law" has opened up a page of sadness in Chinese history. From a feudal private society, a country with a hierarchical system of law, China has become a weak and decadent and willing to sell the country to the qing court. For, as Marx once said, "the thoughts of the ruling age are the thoughts of the ruling class" (Marx, 1924, "The thoughts of the ruling age"), which is like a vicious infectious disease, spreading to every corner of China.

Anyhow, float with Ah Q, it represents the two countries social backwardness, exuviate to farmers in the image of the typical character, but in Lu Xun's ah Q, the "spiritual victory method" also reflects the opposite the typical nature of the Chinese nation, especially in the colonial period.

\section{The Art of Chi Pheo and The True Story of $A h Q$}

Two works have similarities and differences also have some special things in there own.

\section{The Similarities.}

\section{Indifferent and objective language.}

Through the content of "Chi Pheo" and "the true biography of Ah Q", the author uses narrative art to depict and shape the inner world of these two typical characters. Both writers construct the relevant plots of the story with their indifferent attitude and objective perspective.

Nam Cao has a truthful description of the real and naked realities of life: the story of a drunkard, the story of the parties fighting each other, the love stories of those who are not three, and so on... When we understand the writer discovered after rootless feeling, writer of the story is not just explain it through those trivial things reflect a completely out of the social system of corruption in the shadow of human rights. Under the system of this society, human beings have been ravaged, human rights have been trampled, and the society is not as good as the cow and horse. Narrator's words as a player, played a another paragraph about Vu Dai Village when "ghosts" of vicious chi float behavior image: put their face, roguing, looted, burning shops, do bad things for landlord when bailiffs, etc. In the objective description of Nam Cao, the reader will not have a creepy feeling, but it is actually the feeling of the writer creating the circle of intention.

Compared with nangao, Lu Xun tells the story of Ah Q in "The True Story of Ah Q", which leads to a meaningless life with his own foolish actions and thoughts. The narrator seems to have nothing to do with $\mathrm{Ah} Q$, and the character of $\mathrm{Ah} \mathrm{Q}$, the appearance of $\mathrm{Ah} \mathrm{Q}$, the identity of $\mathrm{Ah} \mathrm{Q}$ and the character of $\mathrm{Ah} \mathrm{Q}$ are all very pitiful and disastrous. However, this is not the intention of $\mathrm{Lu}$ Xun's writers. Lu Xun wanted to reveal the weakness of a Chinese society in an objective way, which further debunked the ignorance of Chinese people. With the intention that art, $\mathrm{Lu}$ Xun has successfully used the indifference and objective presentation style, but also contains the writer's social sorrow in the world of reality, love the fate of the people's sympathy.

In modern Chinese literature, Lu Xun's works have been immortal. As a giant of modern Chinese literature, Lu Xun's works are not only popular at home, but also abroad. Vietnam is one of them. Lu Xun's works mainly describe the suffering and fate of the lower peasants and adhere to the humanitarian standpoint. In Vietnam, the 
writer who came close to Lu Xun was Nam Cao, an outstanding writer in Vietnam's modern literary scene. Two writers of different nationalities exhibit similar creative tendencies due to similar creative environments. Vietnam readers read $\mathrm{Lu}$ Xun's works tend to think of meteorological work, also, the meteorological novels also reminiscent of Lu Xun's novel, the reader read Lu Xun's "Ah Q" image is associated with the meteorological "Chi Pheo".

\section{Personalized language}

Nam Cao and Lu Xun also used the unique personalised language. The dialogue content of the characters clearly reflects the characters' character characteristics. When zhiyu is waiting for his master, the writer of Nam Cao has little description of the language of the characters, which reflects the willingness of the peasants who live as slaves. But when he came out of prison, his personality changed, and he shouted and shouted, burned and robbed all day, and his good character was replaced by rogue and rude language. But when the bully saw the old fox, he still bowed his head and served him respectfully.

In "Ah Q", Lu Xun paid special attention to each sentence of Ah Q characters, which set off the basic characteristics of Ah Q character: in the face of the strong, Ah Q summed up. In the face of the weak, Ah Q is weak and conceited.

\section{The Differences Between The True Story of $A h Q$ and Chi Pheo \\ Linear and nonlinear presentation techniques}

The work of AQ is presented according to certain procedures, and the appearance of the characters and their actions and the time of occurrence follow the evolution of the sequence. "Gone with the wind" uses different statements. The first image of the work is not the beginning of the image, the story structure is arranged by the characters' past and present. Each writer chooses different statements for himself. Lu Xun stated in chronological order that Nam Cao did not follow the traditional way of presentation, but the two writers emphasized the ideological value of the work with different characteristics.

"Finishing touch" and elaborating techniques

If Nam Cao meticulously depicts the ugly face and face like a knife cut from prison; His wife, with his sharp teeth and his teeth, is the only one who uses the "finishing touch" method to describe the appearance of Ah Q, which is a simple description of Ah Q's appearance: long pigtails and scars on his face. When describing wang hu, the writer noticed that a whisker was characteristic of him. Although the two writers chose different descriptive techniques, they obviously highlighted the main character traits of the characters.

\section{Description of characters' psychology and action}

Nam Cao has been focusing on exploring the inner world of characters. The mood and thoughts of Chi Pheo are reflected through the process of their psychological evolution, which is based on the author's ingenious description of the brushwork to show the heart, body and character of the person who checks the cheque. The characters in Lu Xun's novels reflect their character through action. Such as Ah Q's character traits are reflected by his actions, curses, curses, and stares.

\section{Conclusion}

In short, "Ah Q of being wild" linear time presentation method was adopted and made "the finishing point technique" to fully demonstrate the Ah Q, a typical action .And the inner world of the characters is a traditional 
Chinese classical narrative text creation style. On the contrary, as for "zhigone" elaborates, the heart and personality characteristics of the typical character with the non-linear presentation technique, which is similar to the creation style of the world's declarative prose in the 20th century. Therefore, Nam Cao's writing is more modern than Lu Xun's. This can be understood as the differences between Lu Xun and Nam Cao, they have 34 years gap. Lu Xun had grown up since the end of the 19th century, while nangao lived in the 20th century. In addition, since the Chinese culture is so extensive and profound, creating the literary achievements has become the pride of the Chinese nation. So, model characters of classical culture have been influenced in the history of Chinese literary world.Including many writers such as $\mathrm{Lu}$ Xun. Therefore, the traditional narrative art used in $\mathrm{Lu}$ Xun's creation is understandable. On the contrary, the modern narration in Vietnam mainly focuses on Chinese characters, which has no influence on Chinese characters in the early 20th century, so the modernization process has evolved extremely quickly. As a writer of the late generation, Nam Cao inherits modern literary creation style and is able to study and accept the precious value of the mid-20th century world literature narrative.

It is important to note that Lu Xun was not only a novelist in ancient literature but also inherited the essence of traditional culture of the Chinese nation. Besides, Lu Xun also approached the end of the 19th century foreign classic literature, such as Russia's nicolas vassili has gogol, Anton kowolski vicki Chekhov and great writer Tolstoy. This is the origin of Lu Xun's new ideas in his literary creation.

\section{References}

Bass. (1982). Q philosophy various psychological connotation of spiritual victory law. Shanxi: Shanxi People's Publishing House. Dang, T. M. (1969). Lu Xun— the example of struggle. Hanoi: Literature Publishing House.

Dang, T. M. (1997). The close relationship between Chinese and Vietnamese literature. Literary journal, (09).

Jiang, K. Y. (1957). The basic knowledge of literature. Beijing: China Youth Publishing House.

Lin, F. (2007). Lu Xun and Chinese culture. Nanjing: Nankai University Press.

Lu, X. (1981). Complete works of Lu Xun. Beijing: People's Literature Publishing House.

Marx. (1924). The thoughts of the ruling age (Q. M. Pham, Trans.). Hanoi: Education Publish house.

Nam, C. (2002). Anthology of nangao novels, volume 1. Hanoi: Literature Publishing House..

Pham, T. C. (2004). Some comparisons between Chi Pheo and Ah Q, “Nam Cao complete set”. Hanoi: People's Public Security Press.

Ruan, S. M. Y. (2013). Comparative study of characters in Lu Xun and nangao's works (Doctoral Thesis, Yunnan university).

Tran, T. L. (2000). On the realism of Nam Cao in the novel, the literature works in the review school. Hanoi: Hanoi National University Press. 